\title{
PENILAIAN RISIKO KESEHATAN KERJA PADA FASILITAS PROSES DI PT X SUMATERA SELATAN
}

\author{
Ayu Seftiani Lestari \\ Program Studi Magister Ilmu Kesehatan Masyarakat, Fakultas Kesehatan Masyarakat \\ Universitas Sriwijaya \\ ayuseftianil@yahoo.com
}

\begin{abstract}
$P T X$ is oil and gas production operations. Production operations are carried out in process facilities, which include oil stations and power plants. The increasing development of oil and gas companies as well as the increasing involvement of the number of workers in this sector have caused the worker very potential to be exposed to hazards in a workplace. HRA is a semi-quantitative risk assessment that determine the magnitude of risk and take control priorities. The purpose of this study was to determine the description of work activities, identify potential hazards, exposure level, and to determine the health risks that may arise, and to determine the control priority based on the Risk Manageability Matrix. This study used descriptive survey, observational approach that uses Walk Through Survey, where results are walking through the checklist, and then analyzed in Matrix Hazard Rating, Matrix Exposure Rating, Risk Matrix, and developed into Risk Manageable Matrix. The results of this study found that the potential hazards included in high-risk category was Noise, moderate risk category was Benzene, Ergonomics and Psychosocial. While the low-risk category is Water Supply. Noise and Benzene are categorized as low Risk Manageability. Due to the control and prevention efforts against the risk of exposure are not optimal, based on these results, expected of PT X can be done by applying noise control with Hearing Conservation Program, such as evaluating noise exposure. As for benzene exposure, expected that there will be biomonitoring measurements for workers and provide a warning sign to use a respirator with an organic vapor cartridge in process facility.
\end{abstract}

Keyword $\quad$ : Health Risk Assessment, Oil And Gas Company, Potential Hazards.

\begin{abstract}
ABSTRAK
PT X merupakan perusahaan operasi produksi minyak dan gas bumi. Kegiatan operasi produksi berpusat di Fasilitas Proses yaitu stasiun pengumpul minyak dan power plant. Meningkatnya perkembangan perusahaan minyak dan gas dan keterlibatan jumlah pekerja di sektor ini menyebabkan kontak terhadap potensi paparan hazard yang berisiko pada pekerja sangatlah besar. Health Risk Assessment adalah salah satu teknik penilaian risiko secara semi-kuantitatif yang dapat mengetahui besarnya risiko dan pengambilan prioritas pengendalian. Tujuan penelitian ini adalah untuk mengetahui deskripsi aktivitas kerja, mengidentifikasi potensial hazard, tingkatan keterpaparan, mengetahui risiko yang mungkin timbul, serta mengetahui prioritas pengendalian berdasarkan Risk Manageability Matrix. Penelitian ini menggunakan metode penelitian survey deskriptif dengan pendekatan observasional yang menggunakan teknik Walk Through Survey, dimana hasil Walk Through dibuat Check list, lalu di analisa dalam Matrix Hazard Rating, Matrix Exposure Rating, Risk Matrix, dan dikembangkan dalam Risk Manageability Matrix. Hasil penelitian ini didapatkan bahwa potensial hazard yang termasuk dalam kategori risiko tinggi ialah kebisingan, kategori risiko sedang ialah benzene, ergonomi dan psikosisal. Sedangkan kategori risiko rendah yaitu water supply. Kebisingan dan Benzene memiliki tingkat pengendalian rendah. Hal tersebut disebabkan karenakan upaya pengendalian serta pencegahan terhadap risiko paparannya belum optimal, sehingga diharapkan PT X dapat melakukan upaya pengendalian kebisingan dengan
\end{abstract}


melaksanakan Program Konservasi Pendengaran (Hearing Conservation Programs), seperti mengevaluasi paparan kebisingan. Sedangkan untuk paparan benzene diharapkan adanya pengukuran biomonitoring pekerja di Fasilitas Proses dan memberikan tanda peringatan kewajiban menggunakan respirator dengan katridge uap organik.

Kata kunci $\quad$ : Penilaian Risiko Kesehatan, Perusahaan Minyak Dan Gas, Potensi Hazard.

\section{PENDAHULUAN}

Pada sektor industri semua perusahaan wajib melakukan tindakan pencegahan terkait pada kecelakaan dan penyakit akibat kerja (Domínguez et al, 2019). Dikarenakan setiap pekerjaan memiliki potensi risiko untuk mengalami kecelakaan kerja ataupun penyakit akibat kerja. Dalam menjalankan suatu bisnis, tenaga kerja memiliki potensi yang besar untuk terpapar hazard dan menimbulkan suatu risiko dalam menjalankan aktivitas kerjanya (Elphiana et al, 2017).

Berdasarkan data International Labour Organization (ILO), setiap tahun terjadi 1,1 juta kematian yang disebabkan oleh penyakit atau yang disebabkan oleh pekerjaan. Sekitar 300.000 kematian terjadi dari 250 juta kecelakaan, dan sisanya adalah kematian yang disebabkan oleh penyakit akibat kerja yang mana dari data tersebut diperkirakan terjadi 160 juta penyakit akibat hubungan pekerjaan baru setiap tahunnya (Lestari $\mathrm{M}$ et al, 2017). Penelitian yang dilakukan oleh Prasetyo RD (2018) di industri pertambangan menunjukkan bahwa kegiatan industri tambang memiliki kecenderungan potensi tingkat risiko sedang dan tinggi. Dalam aktivitas kerjanya, tenaga kerja dapat terpapar berbagai macam jenis hazard mulai dari hazard heat stress akibat dari ikilm kerja yang panas, kebisingan akibat dari mesin dan peralatan kerja, debu dan gas serta kelelahan kerja (Prasetyo RD, 2018).

Menurut perkiraan terbaru yang dikeluarkan oleh Organisasi Perburuhan Internasional (ILO), 2,78 juta pekerja meninggal setiap tahun karena kecelakaan kerja dan penyakit akibat kerja. Sekitar 2,4 juta (86,3 persen) dari kematian ini dikarenakan penyakit akibat kerja, sementara lebih dari 380.000 (13,7 persen) dikarenakan kecelakaan kerja (ILO, 2018). Setiap tahun, ada hampir seribu kali lebih banyak kecelakaan kerja non-fatal dibandingkan kecelakaan kerja fatal (ILO, 2018). Maka dari itu, pencegahan terkait kecelakaan dan penyakit akibat kerja dilakukan untuk memberikan perlindungan kepada pekerja agar tetap sehat dan produktif dalam melakukan aktivitas pekerjaannya.

Penyakit akibat kerja muncul hanya setelah terjadinya paparan kumulatif dan/atau periode laten (EU-OSHA, 2007). Maka dari itu paparan hazard yang terus menerus dalam waktu yang cukup lama tidak bisa dianggap sepeleh. Perusahaan perlu melakukan upaya dalam menilai risiko kesehatan kerja agar dapat diketahui upaya perbaikan serta rekomendasi pengendalian yang tepat sasaran. HRA (Health Risk Assessment) merupakan sebuah metode penilaian risiko yang disebabkan oleh faktor-faktor yang mengganggu kesehatan.

Sebagai salah satu upaya dalam melakukan pencegahan terhadap penyakit akibat kerja maka HRA (Health Risk Assessment) merupakan teknik yang tepat untuk digunakan. HRA adalah salah satu teknik penilaian risiko secara semi-kuantitatif yang dapat mempermudah mengetahui besarnya risiko dan pengambilan prioritas pengendalian (Ayudinta MA, 2016).

PT X adalah perusahaan swasta nasional yang telah berhasil menempatkan diri sejajar dengan perusahaan minyak dan gas 
internasional yang beroperasi di Indonesia. Aktivitas kegiatan yang berlangsung pada PT $\mathrm{X}$ adalah kegiatan operasi produksi minyak dan gas bumi yang terdiri dari eksplorasi dan proses produksi. Selain kegiatan eksplorasi dan proses produksi terdapat fasilitas pendukung untuk mendukung keberlangsungan kegiatan operasional perusahaan seperti area mess, perkantoran dan kantin.

Jika ditinjau dari berbagai aktivitas pekerjaan yang dilakukan setiap harinya di area kerja PT X serta seiring dengan meningkatnya perkembangan perusahaan minyak dan gas, keterlibatan jumlah pekerja di sektor ini juga meningkat demikian pula kontak pekerja terhadap berbagai hazard yang ada di lingkungan kerja, tentu potensi timbulnya bermacam-macam hazard yang berisiko terhadap pekerja sangat mungkin terjadi.

Dilihat dari permasalahan diatas, Health Risk Asessment yang memadai menjadi penting karena bertindak sebagai sistem proteksi dan program kesehatan kerja di suatu proses industri dalam rangka menilai dan mengelola risiko kesehatan kerja. Hal ini pun diperkuat oleh surat edaran SKK Migas Nomor EDR-0109/SKKMF000/2017/S5 tentang Key Peformance Indicator Occupational Health \& Industrial Hygiene yang menjadikan pelaksanaan HRA merupakan program leading mandatory. Oleh sebab itu, maka perlu dilakukan penilaian risiko kesehatan pada pekerja perusahaan minyak dan gas bumi di PT X Sumatera Selatan.

\section{METODE}

Penelitian ini menggunakan metode penelitian survey deskriptif, dengan pendekatan observasional yang menggunakan teknik Walk Through Survey, dimana hasil Walk Through dibuat check list, lalu dianalisa dalam matrix Hazard Rating, Matrix
Exposure Rating, Risk Matrix dan dikembangkan dalam Risk Manageability Matrix. Adapun langkah-langkah yang akan dilakukan dalam penelitian ini, yaitu: mempelajari hasil walk through survey dalam bentuk check list dan flow sheet, kemudian mengidentifikasi seluruh potensi hazard kesehatan dalam bentuk fisik, kimia, biologi, ergonomi, dan psikososial pada seluruh kegiatan di Fasilitas Proses (stasiun pengumpul minyak dan power plant) di PT X Sumatera Selatan Tahun 2021 serta menilainya dengan standar penilaian hazard (hazard ratings) dan dikembangkan ke dalam matrik hazard.

Tabel 1. Hazard Rating

\begin{tabular}{|c|c|}
\hline $\begin{array}{l}\text { Hazard } \\
\text { Rating }\end{array}$ & $\begin{array}{c}\text { Definisi } \\
\text { (Potential Hazard in causing health } \\
\text { problems in humans) }\end{array}$ \\
\hline $\mathbf{0}$ & $\begin{array}{l}\text { Tidak menyebabkan cedera/ gangguan } \\
\text { kesehatan }\end{array}$ \\
\hline 1 & $\begin{array}{l}\text { Slight Injury } \\
\text { (Menyebabkan cedera ringan dan sakit } \\
\text { ringan, biasanya menyebabkan gangguan } \\
\text { kenyamanan, tidak mengganggu kinerja } \\
\text { dan tidak menyebabkan kecacatan) }\end{array}$ \\
\hline 2 & $\begin{array}{l}\text { Minor Injury } \\
\text { (Menyebabkan cedera ringan dan sakit } \\
\text { ringan tetapi mengganggu kinerja atau } \\
\text { hilangnya waktu kerja) }\end{array}$ \\
\hline 3 & $\begin{array}{l}\text { Major Injury } \\
\text { (Menyebabkan cedera serius dan penyakit, } \\
\text { mengakibatkan terganggunya kinerja serta } \\
\text { hilangnya waktu kerja yang lama) }\end{array}$ \\
\hline 4 & $\begin{array}{l}\text { Permanent Total Disability or Fatality } \\
\text { (Menyebabkan cacat permanen total atau } \\
\text { kematian, mis. Hidrogen Sulfida, } \\
\text { Asbestos dan Benzene) }\end{array}$ \\
\hline 5 & $\begin{array}{l}\text { Multiple Fatalities } \\
\text { (Menyebabkan kematian dalam jumlah } \\
\text { yang besar) }\end{array}$ \\
\hline \multicolumn{2}{|c|}{ Sumber: (Shell HSE Committee, 2001) } \\
\hline
\end{tabular}


Lalu, seluruh potensial hazard yang telah teridentifikasi dilakukan penilaian paparan terhadap pekerja (exposure) dengan standar penilaian keterpaparan (exposure rating) dan dikembangkan ke dalam matrik exposure.

Tabel 2. Exposure Rating

\begin{tabular}{|c|c|c|}
\hline \multicolumn{2}{|c|}{ Exposure Rating } & \multirow{2}{*}{\begin{tabular}{l}
\multicolumn{1}{c}{ Definisi } \\
$\begin{array}{l}\text { Paparan tidak menimbulkan } \\
\text { gangguan kesehatan }\end{array}$
\end{tabular}} \\
\hline $\mathrm{A}(1)$ & Very Low & \\
\hline B (2) & Low & $\begin{array}{l}\text { Paparan masih dibawah ambang } \\
\text { batas, masih terkontrol dengan } \\
\text { baik melalui criteria screening } \\
\text { dan performance }\end{array}$ \\
\hline $\mathrm{C}(3)$ & Medium & $\begin{array}{l}\text { Paparan Mendekati NAB } \\
\text { namun masih memenuhi } \\
\text { kriteria screening dan } \\
\text { performance. Kontrol terhadap } \\
\text { nilai paparan dapat mengalami } \\
\text { perubahan. }\end{array}$ \\
\hline D (4) & High & $\begin{array}{l}\text { Paparan diatas NAB, sudah } \\
\text { tidak dapat dikontrol melalui } \\
\text { kriteria screening dan } \\
\text { performance namun secara } \\
\text { kontinu terus bertambah, jauh } \\
\text { melebihi NAB. }\end{array}$ \\
\hline E (5) & Very High & $\begin{array}{l}\text { Paparan jauh melebihi NAB, } \\
\text { sudah menimbulkan gangguan } \\
\text { pada individu yang terpapar }\end{array}$ \\
\hline
\end{tabular}

Sumber: (Shell HSE Committee, 2001)

Setelah itu melakukan penilaian terhadap risk masing-masing hazard berdasarkan jenis hazard dan exposure-nya dalam lingkungan kerja dengan cara matrik exposure dikalikan dengan matrik hazard dan terakhir membuat Risk Manageability Matrix.

\section{HASIL}

Penilaian risiko kesehatan kerja dilakukan pada dua lokasi pada Fasilitas Proses di PT X Sumatera Selatan, yaitu stasiun pengumpul minyak dan power plant. Stasiun pengumpul minyak merupakan tempat dimana fluida yang berasal dari sumur - sumur dikumpulkan untuk dilanjutkan pada proses pemisahan antara minyak, air dan gas sehingga bisa menghasilkan produk crude oil sedangkan power plant merupakan penunjang untuk penyedia energi listrik di area perusahaan.

\section{Identifikasi Potensi Hazard dan Tingkat Keterpaparan Hazard Fisika (Kebisingan)}

Potensial hazard fisik kebisingan di Fasilitas Proses yang ditemukan pada stasiun pengumpul minyak yaitu bersumber dari mesin pompa WIP (Water Injection Pump) yang beroperasi setiap harinya sedangkan pada power plant berasal dari mesin genset dan fan radiator yang digunakan sebagai penyedia energi listrik untuk seluruh area perusahaan. Pengukuran dilakukan dengan pendekatan pengukuran area dengan menggunakan Sound Level Meter. Hasil pengukuran paparan kebisingan area menunjukan hasil di atas NAB (85 dBA) sebagai kadar/ intensitas rata - rata tertimbang waktu (TWA) yang dapat diterima oleh pekerja tanpa mengakibatkan penyakit/ gangguan kesehatan dalam pekerjaan sehari hari untuk waktu tidak melebihi $8 \mathrm{jam} / \mathrm{hari}$ atau $40 \mathrm{jam} / \mathrm{minggu}$. Hasil pengukuran di area stasiun pengumpul minyak yang berlokasi di titik area WIP didapatkan sebesar 91,1 dBA dan di area Power Plant Kaji yang berlokasi di titik area ruang genset didapatkan sebesar 94,7 dBA.

\section{Hazard Kimia (Benzene)}

Pengukuran paparan benzene dilakukan dengan pendekatan pengukuran area. Pengukuran area dilakukan untuk mendapatkan gambaran paparan di lokasi sumber. Teknik pengukuran benzene menggunakan sampling aktif dengan metode sampling dan analisa berdasarkan NIOSH 1501. Alat yang digunakan pada pengukuran benzene meliputi Universal Sampling Pump 
dan Rotameter dengan media sampel charcoal.

Hasil pengukuran sampel area Fasilitas Proses menunjukkan kadar benzene ND (Not Detected) karena kadar yang sangat rendah atau dibawah detection limit $(<0,092 \mathrm{ppm})$. Pola kerja operator Fasilitas Proses berpotensi adanya paparan terhadap uap benzene, khususnya pada saat melakukan inspeksi dan draining di area skimming pit kurang lebih 2 kali/ shift dengan durasi 15 - 20 menit. Shift pagi biasanya di lakukan pada pukul 08.00 WIB dan shift siang pukul 11.00 WIB. Peluang waktu paparan antara $30-40$ menit dalam 1 (satu) shift.

\section{Hazard Biologi (Water Supply)}

Pengukuran paparan hazard biologi terkait dengan water supply (air higiene sanitasi dan air minum) di Fasilitas Proses PT X Sumatera Selatan diketahui bahwa untuk keperluan air minum setiap harinya, semua pekerja di PT X Sumatera Selatan menggunakan air galon dari salah satu merk air mineral di Indonesia, sedangkan untuk keperluan hygiene dan sanitasi perusahaan, PT $X$ Sumatera Selatan memiliki Unit Pengolahan Air tersendiri yang mana sumber air berasal dari sungai Batang Hari Leko.

Tabel 3. Hasil Pengukuran Lab Air Minum di Fasilitas Proses PT X Sumatera Selatan

\begin{tabular}{llcccc}
\hline No. & $\begin{array}{l}\text { Deskripsi } \\
\text { Pengukur } \\
\text { an }\end{array}$ & $\begin{array}{l}\text { Total } \\
\text { Kolif } \\
\text { orm }\end{array}$ & $\begin{array}{l}\text { Faeca } \\
\text { I Coli }\end{array}$ & $\begin{array}{l}\text { Baku } \\
\text { Mutu }\end{array}$ & Unit \\
\hline 1. & $\begin{array}{l}\text { Air } \\
\text { Minum }\end{array}$ & 0 & 0 & 0 & $\begin{array}{l}\text { Koloni/ } \\
100 \mathrm{~mL}\end{array}$ \\
\hline
\end{tabular}

Tabel 4. Hasil Pengukuran Lab Air Hiygiene Sanitasi di Fasilitas Proses PT X Sumatera Selatan

\begin{tabular}{|c|c|c|c|c|}
\hline No. & $\begin{array}{l}\text { Deskripsi } \\
\text { Pengukuran }\end{array}$ & $\begin{array}{l}\text { Besi } \\
\text { (Fe) }\end{array}$ & $\begin{array}{l}\text { Baku } \\
\text { Mutu }\end{array}$ & Unit \\
\hline 1. & $\begin{array}{l}\text { Air Hygiene } \\
\text { Sanitasi } \\
\text { Fasilitas } \\
\text { Proses }\end{array}$ & 0,32 & 1 & $\mathrm{mg} / \mathrm{L}$ \\
\hline
\end{tabular}

Berdasarkan pemeriksaan lengkap yang dilakukan pada sampel air di Fasilitas Proses (Koliform, Faecal Coli dan Fe), didapatkan bahwa air yang digunakan masih memenuhi standar kesehatan Peraturan Menteri Kesehatan No. 492 Tahun 2010 tentang Baku Mutu Air Minum dan Peraturan Menteri Kesehatan No. 32 Tahun 2017 tentang Baku Mutu Air Higiene Sanitasi.

\section{Hazard Ergonomi}

Pengukuran paparan hazard ergonomi dilakukan pada aktivitas kerja yang ada di Fasilitas Proses (Power Plant) untuk aktivitas PM Genset. Pengukuran ini dilakukan dengan menggunakan Checklist Washington Administrative Code (WAC).

Berdasarkan hasil pengukuran ditemukan bahwa pekerjaan yang sering dilakukan pada Fasilitas Proses khususnya di power plant saat aktivitas pekerjaan PM Genset merupakan aktivitas pekerjaan manual handling yang berulang (repetitive) serta aktivitas mengangkat (lifting), menarik (pulling) dan mondorong (pushing). Aktivitas manual handling tersebut teridentifikasi terutama pada tahapan pekerjaan PM Genset di power plant yaitu pada aktivitas membongkar/ memasang busi, membongkar/ memasang guard fan radiator, membersihkan guard dengan air bertekanan, membersihkan saringan udara engine dengan udara bertekanan, drain oil cooler engine dan membersihkan engine.

Aktivitas pekerjaan PM Genset dilakukan secara rutin setiap 1200 jam operasi. Durasi pelaksanaan pekerjaan PM Genset kurang lebih salaam 4 jam dengan 4 orang teknisi. Beberapa pekerja ditemukan bekerja dengan awkaward posture (postur janggal), hal tersebut dikarenakan ukuran engine genset yang cukup besar serta posisi mesin yang cukup tinggi menyebabkan teknisi yang melakukan kegiatan PM Genset harus menyesuaikan posisi tubuh mereka untuk dapat melaksanakan setiap tahapan 
pekerjaannya (jongkok, berdiri, mendongak ke atas ataupun menunduk).

Jika posisi kerja tersebut dilakukan secara berulang-ulang dengan posisi kerja yang janggal, maka dapat mengakibatkan gangguan Kesehatan yaitu MSDs (Musculoskletal Disorders) yang memiliki gejala seperti nyeri pada leher, nyeri pada bagian kaki dan nyeri pinggang (low back pain).

\section{Hazard Psikososial}

Pengukuran paparan hazard psikososial dilakukan pada pekerja permanen yang ada beroperasi di Fasilitas Proses PT X Sumatera Selatan. Pengukuran ini dilakukan dengan menggunakan Kuesioner Penilaian Risiko Kesehatan Kerja berdasarkan Permenaker No. 05 Tahun 2018 tentang Keselamatan dan Kesehatan Kerja Lingkungan Kerja.

Berdasarkan hasil kuesioner, 16 responden pekerja di Fasilitas Proses didapatkan 8 orang pekerja berpotensi risiko stress kerja tinggi. Dilihat dari hasil kuesioner risiko stress kerja yang dialami pekerja yaitu karena adanya beban berlebih kuantitatif yang merupakan kondisi dimana responden mengalami desakan waktu dalam melakukan tugas atau pekerjaanya.

Selain itu, adanya konflik peran yaitu keadaan dimana responden mengalami pertentangan antara tugas - tugas yang harus ia lakukan dengan tanggung jawab yang ia miliki, tugas - tugas yang harus ia lakukan dipadangan sebagai bukan bagian dari bagian pekerjaanya.

Tabel 5. Hazard Matrix

\begin{tabular}{l|l|c}
\hline \multicolumn{1}{c|}{ Elemen } & $\begin{array}{l}\text { Gangguan Kesehatan yg } \\
\text { Mungkin Timbul }\end{array}$ & Score \\
\hline Fisik & $\begin{array}{l}\text { Noise Induced Hearing } \\
\text { Kebisingan }\end{array}$ & 4 \\
Kimia & $\begin{array}{l}\text { Leucaemia } \\
\text { Benzene } \\
\text { Biologi } \\
\text { Water Supply }\end{array}$ & $\begin{array}{l}\text { Water Borne Diseases } \\
\text { (Tifoid, Kolera, } \\
\text { Gastroenteritis dan }\end{array}$ \\
\hline
\end{tabular}

\begin{tabular}{l|l|c}
\hline Ergonomi & $\begin{array}{l}\text { Leptospirosis) } \\
\text { Musculoskletal Disorders } \\
\text { (MSDs) }\end{array}$ & 3 \\
Psikososial & Work Related Stress & 2 \\
\hline
\end{tabular}

Hasil kajian terhadap hazard yang ada pada Fasilitas Proses di PT X Sumatera Selatan, kemudian diberi score. Pemberian score lalu dimasukkan kedalam matrik identifikasi hazard (hazard rating) dan matrik penilaian paparan (exposure rating), untuk lebih detail dalam pemberian score dapat dilihat pada tabel 5 dan tabel 6 .

Tabel 6. Hazard Matrix

\begin{tabular}{l|l|c}
\hline \multicolumn{1}{c|}{ Elemen } & \multicolumn{1}{|c|}{ Exposure Rating } & Score \\
\hline $\begin{array}{l}\text { Fisik } \\
\text { Kebisingan } \\
\text { Kimia }\end{array}$ & Tinggi (melebihi NAB) & 4 \\
Benzene & Rendah (dibawah NAB) & 2 \\
Biologi & Rendah (Memenuhi Baku & 2 \\
Water Supply & Mutu Air Minum dan Air & \\
Ergonomi & Higiene Sanitasi) & \\
Psikososial & Tinggi (Berisiko) & 4 \\
\hline
\end{tabular}

\section{Penilaian Risiko Kesehatan}

Setelah melakukan penilaian pada potensial hazard dan tingkat keterpaparan (exposure) pada Fasilitas Proses di PT X Sumatera Selatan, maka langkah selanjutnya adalah melakukan penilaian risiko. Penilaian Risk Matrix didapatkan dari hasil perkalian antara Hazard Rating dengan Exposure Rating ( $\mathrm{R}=\mathrm{HxE})$, untuk lebih detail dapat dilihat pada tabel 7 dan tabel 8 .

Dari tabel 8 dapat dilihat hasil perkalian antara Hazard Rating dan Exposure Rating serta tingkat pengendalian. Tingkat pengendalian yang dimaksud pada tabel 8 tersebut ialah menunjukkan tingkatan upaya pengendalian yang sudah dilakukan oleh perusahaan dan bagaimana dengan dampaknya.

Hasil dari penilaian Risk Matrix selanjutnya juga di representasikan kedalam Risk Manageability Matrix, sebagai gambaran tingkat risiko dan prioritas tingkat 
pengendalian yang harus dilakukan di Fasilitas Proses PT X Sumatera Selatan. Kolom yang berada pada barisan vertikal (dari bawah ke atas) merupakan tingkatan risiko (Risk). Semakin ke atas kolom tersebut maka semakin tinggi tingkatan risiko hazard.

Kolom yang berada pada baris horizontal (bagian bawah) merupakan tingkatan pengendalian hazard. Dari kolom manageability ini, dapat dilihan tingkat kesulitan pengendalian suatu risiko di Fasilitas Proses PT X Sumatera Selatan. Penilaian pada kolom pengendalian (Manageability) ditunjukkan dengan semakin ke kanan kolom tersebut maka tingkatan pengendalian hazard tersebut semakin tinggi yaitu makin mudah untuk dikendalikan dan sebaliknya.

Tabel 7. Risk Matrix

\begin{tabular}{ccccc}
\hline \multicolumn{5}{c}{ Exposure Rating } \\
\hline $\begin{array}{c}\text { Hazard } \\
\text { Rating }\end{array}$ & 1 & 2 & 4 & 5 \\
\hline 1 & & & \\
2 & & Psikososial \\
3 & & Water Supply & Ergonomi \\
4 & Benzene & Kebisingan \\
5 & & & \\
\hline
\end{tabular}

Keterangan:

: Kategori Risiko Rendah

Kategori Risiko Sedang

Kategori Risiko Tinggi

Tabel 8. Risk Matrix dan Tingkat Pengendalian

\begin{tabular}{|lcccc|}
\hline \multicolumn{1}{|c|}{ Elemen } & $\begin{array}{c}\text { Low } \\
(\leq \mathbf{6})\end{array}$ & $\begin{array}{c}\text { Med } \\
\mathbf{( 7 - 1 2 )}\end{array}$ & $\begin{array}{c}\text { High } \\
\mathbf{( \geq \mathbf { 1 3 } )}\end{array}$ & $\begin{array}{c}\text { Tingkat } \\
\text { Pengendalian }\end{array}$ \\
\hline $\begin{array}{l}\text { Fisik } \\
\text { Kebisingan } \\
\text { Kimia }\end{array}$ & & & $\sqrt{ }$ & Sedang \\
$\begin{array}{l}\text { Benzene } \\
\text { Biologi } \\
\text { Water }\end{array}$ & & $\sqrt{ }$ & & Sedang \\
$\begin{array}{l}\text { Supply } \\
\text { Ergonomi }\end{array}$ & $\sqrt{ }$ & & & Tinggi \\
\hline
\end{tabular}
Psikososial
Keterangan:
Tingkat Pengendalian:
Rendah (R): Masalah tersebut belum dikelola dan paparan belum dikendali
Sedang (S): Masalah tersebut sudah dikelola tapi paparan masih belum terkendali
Tinggi (T): Masalah tersebut sudah dikelola dan paparan sudah terkendali

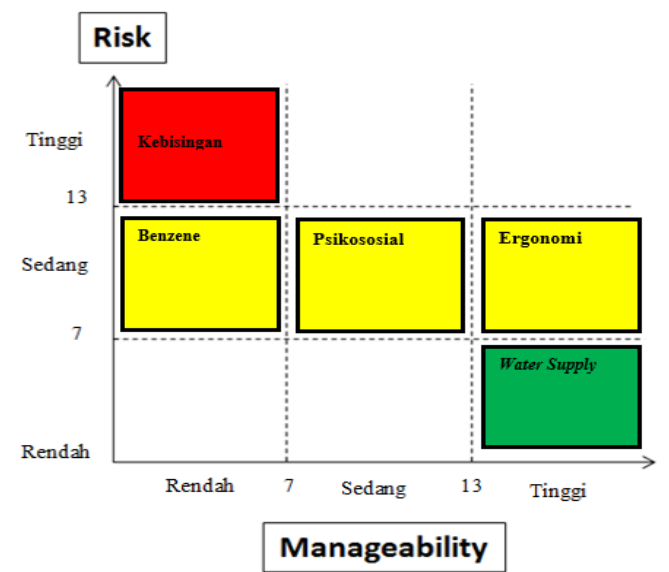

Gambar 1. Risk Manageability Matrix

\section{PEMBAHASAN}

\section{Kategori Risiko Tinggi \\ Kebisingan}

Potensial hazard pada Fasilitas Proses yang termasuk risiko kategori tinggi yaitu kebisingan. Paparan kebisingan area di Fasilitas Proses PT X Sumatera Selatan menunjukan hasil di atas NAB (85 dBA) dengan hasil pengukuran di area stasiun pengumpul minyak yang berlokasi di titik area WIP didapatkan sebesar 91,1 dBA dan di area power plant yang berlokasi di titik area ruang genset didapatkan sebesar 94,7 dBA.

Berdasarkan Permenaker No. 05 Tahun 2018 tentang Keselamatan dan Kesehatan Kerja Lingkungan Kerja, dengan intensitas kebisingan tersebut seharusnya waktu paparan terhadap pekerja hanya di perbolehkan $1-2$ jam perhari. Selain itu, standar lain yang juga mengatur tentang Nilai Ambang Batas Kebisingan (NAB) kebisingan, yaitu National Institute for Occupational Safety and Health (NIOSH) 
menyebutkan bahwa Recommended Exposure Limit (REL) untuk paparan kebisingan di tempat kerja adalah $85 \mathrm{dBA}$ selama 8 jam.

Paparan kebisingan yang diterima oleh pekerja pada Fasilitas Proses di PT X Sumatera Selatan mendekati NAB yang bisa saja berpotensi sewaktu - waktu mengalami perubahan hingga melewati NAB. Hal yang sama akan terjadi pada paparan kebisingan area yang melebihi $\mathrm{NAB}$, sehingga hazard kebisingan berpotensi menimbulkan risiko gangguan kesehatan, yaitu gangguan pendengaran atau kerusakan pada telinga baik bersifat sementara bahkan permanen setelah terpapar untuk jangka waktu tertentu tanpa proteksi yang memadai (Chusna et al, 2017).

Dengan terjadinya gangguan pendengaran atau kerusakan pada telinga pekerja, menyebabkan pekerja dapat kehilangan salah satu fungsi indera yang menyebabkan kesalahan dalam komunikasi/ instruksi kerja sehingga dapat menurunkan produktifikas pekerja bahkan membahayakan keselamatannya (Pramesti \& Damayanti, 2017).

\section{Kategori Risiko Sedang}

\section{Benzene}

Potensial hazard pada Fasilitas Proses yang termasuk risiko kategori sedang yaitu potensial hazard kimia Benzene. Potensial hazard kimia benzene didapatkan hasil bahwa pengukuran sampel area dibawah detection limit. Meskipun hasil pengukuran berada di bawah detection limit, tidak bearti bahwa paparan benzene di area tersebut akan sama hasilnya sepanjang waktu. Karena pada dasarnya data pengukuran yang diperoleh hanya menggambarkan kondisi pada saat sampling dilakukan dan hanya sebatas menunjukkan potensial risiko saja.

Selain pengukuran area, pengukuran personal sangat diperlukan dengan menggunakan metode pengukuran biomonitoring. Hal ini dikarenakan benzene merupakan bahan kimia yang menjadi perhatian utama karena diklasifikasikan sebagai A1 - Confirmed as human carcinogenic berdasarkan ACGIH (American Conference Goverenmental Industrial Hygienist), yang dapat menyebabkan leukemia (kanker darah), selain itu benzene bukan hanya dapat masuk melalui inhalasi, tetapi ACGIH juga memberikan catatan bahwa benzene juga dapat masuk ke dalam tubuh melalui kulit (skin absorption) (Susilaningtyas et al, 2018).

Berdasarkan Agency for Toxic Substances and Disease Register (ATSDR), bahan kimia berbahaya dan beracun yang terdapat di dalam kandungan minyak mentah adalah benzene, toluene, xylene, ethylene, TPH (Total Petroleum Hydrocarbon), dan Polycyclic Aromatic Hydrocarbon (PAHs). Dari keenam bahan kimia tersebut, paparan benzene merupakan bahan kimia yang menyebabkan gangguan kesehatan serius (Kartikasari et al, 2016).

\section{Ergonomi}

Potensial hazard pada Fasilitas Proses yang termasuk risiko kategori sedang yaitu Ergonomi. Jika dilihat dari hasil pengukuran dengan menggunakan Checklist Washington Administrative Code (WAC), maka aktivitas pekerjaan tersebut memiliki tingkat risiko ergonomi sedang. Tingkat risiko sedang tersebut dipicu dari postur tubuh janggal yang dilakukan secara berulang terutama pada bagian leher, bahu, lengan dan tangan (pada saat aktivitas mencengkeram hand tools). Beban kerja yang berlebih, frekuensi/ pengulangan, waktu paparan, postur tubuh saat bekerja, jumlah beban mekanis, intensitas kekuatan yang tinggi, aktivitas manual handling, pengulangan, pengerahan tenaga besar, peregangan otot, kondisi lingkungan dan psikososial yang tidak baik merupakan faktor risiko terjadinya WMSDs 
atau Work Related Musculoskeletal Disorders (Dewi N, 2020).

Gangguan kesehatan kerja yang sering dialami pekerja di Indonesia, menurut penelitian yang dilakukan oleh Asnel \& Pratiwi (2020) terhadap 482 pekerja di 12 kabupaten/kota di Indonesia, $16 \%$ di antaranya mengalami gangguan kesehatan kerja berupa gangguan musculoskeletal (Asnel \& Pratiwi, 2020). Work Related Musculoskeletal disorders (WMSDs) adalah penyakit akibat kerja yang ditimbulkan akibat pekerjaan yang mana menggambarkan berbagai bentuk cidera, nyeri atau kelainan pada sistem otot rangka yang terdiri dari jaringan saraf, otot, tulang, ligamen, tendon dan sendi. WMSDs merupakan masalah yang signifikan pada pekerja (Safitri et al, 2017).

Berdasarkan penilaian risiko ergonomi yang dilakukan pada pekerja aktivitas PM Genset dan laundry di PT X dengan menggunakan Checklist Washington Administrative Code (WAC) didaptkan hasil bahwa bagian tubuh yang sangat berisiko saat melakukan aktivitas pekerjaan PM Genset dan juga laundry yaitu bagian leher, tangan/ lengan dan kaki. Bagian - bagian tersebut jika mengalami cedera makan akan sangat membahayakan pekerja bersangkutan sehingga tidak bisa melakukan aktivitas kerja sebagaimana mestinya secara normal.

Penelitian yang dilakukan Rohani et al (2018) menunjukkan hasil bahwa pada aktivitas preventive maintenance mesin alat berat sebagian besar berisiko terkena WMSD di bagian tubuh terutama pada pergelangan tangan, punggung, leher, bahu, dan kaki. Hal ini merupakan indikasi perlunya menerapkan prinsip ergonomi dalam desain workstation terkait aktivitas PM tersebut. Prinsip ergonomi sangat penting karena saat pekerja melakukan suatu aktivitas kerja, maka otot tubuh pekerja akan tegang oleh postur tubuh yang canggung, gerakan yang berulang yang mana akan sangat berpengaruh pada musculoskeletal.

\section{Psikososial}

Potensial hazard pada Fasilitas Proses yang termasuk risiko kategori sedang yaitu Psikososial. Hasil pengukuran hazard psikososial menggunakan kuesioner Penilaian Risiko Kesehatan Kerja berdasarkan Permenaker No. 05 Tahun 2018 tentang Keselamatan dan Kesehatan Kerja Lingkungan Kerja. Aspek yang dinilai meliputi Ketaksaan Peran, Konflik Peran, Beban Berlebih Kuantitatif, Beban Berlebih Kualitatif, Pengembangan Karir dan Tanggung Jawab terhadap Orang Lain.

Pengukuran Hazard Psikososial ini bermaksud untuk menilai potensi risiko stress pada pekerja terhadap pekerjaannya bukan untuk mendiagnosa stress. Meskipun demikian hasil dari kuesioner ini sangat berperan penting dalam mengidentifikasi adanya paparan hazard psikososial di dalam lingkungan kerja pekerka pada Fasilitas Proses di PT X Sumatera Selatan.

Hasil menunjukkan bahwa dari 16 total responden di dapatkan hasil bahwa 8 orang pekerja memiliki tingkat risiko stress kerja tinggi. Salah satu faktornya disebabkan karena tuntutan pekerjaan yang tinggi dan lokasi kerja yang jauh (bekerja di remote area). Menurut WHO (2003), Stres kerja akan muncul akibat respon yang ditunjukkan tenaga kerja ketika dihadapkan pada tuntutan kerja dan tekanan kerja yang tidak sesuai dengan pengetahuan dan kemampuannya, dimana hal ini merupakan suatu tantangan untuk diatasi oleh tenaga kerja yang bersangkutan.

Stress kerja memberikan dampak yang merugikan seperti, absenteisme dan rendahnya performa kerja. Efek jangka panjang yang ditimbulkan dari stres kerja yaitu berupa penyakit, seperti gangguan 
lambung, gangguan tulang belakang dan otot, hipertensi hingga penyakit jantung. Penyakit tersebut merupakan penyakit yang menyumbang angka kesakitan, kecacatan dan kematian di negara industri (ILO, 2013).

Maka dari itu, pengelolaan stress kerja sangat diperlukan untuk dilakukan di perusahaan. Menurut WHO (2010), terdapat 3 langkap dalam pencegahan dan penanggulangan stress kerja yaitu pencegahan primer, seperti pengembangan organisasi dan manajemen serta penyesuian ergonomi dalam desain lingkungan kerja, pencegahan sekunder, seperti memberikan Pendidikan dan pelatihan kepada pekerja terkait stress kerja dan pencegahan tersier yaitu dengan meningkatkan sensitivitas dan respon sistem manajemen serta meningkatkan pelayanan kesehatan kerja khususnya terkait stress kerja (layanan konseling).

\section{Kategori Risiko Rendah}

\section{Water Supply}

Kategori risiko rendah pada penilaian risiko kesehatan kerja pada Fasilitas Proses di PT X Sumatera Selatan ialah hazard biologi terkait dengan water supply. Sumber air baku yang digunakan oleh PT X Sumatera Selatan sepenuhnya berasal dari Sungai Batang Hari Leko. Sungai ini berjarak kurang lebih $60 \mathrm{~km}$ dari lokasi PT X Sumatera Selatan. Sedangkan untuk air minum dan memasak menggunakan air galon dari salah satu merk air mineral di Indonesia. Sumber air dari Sungai Batang Hari Leko selanjutnya melewati proses pengolahan di WTP (Water Treatment Plant) agar dapat digunakan ke semua area di perusahaan.

Air minum dan air sanitasi harus memenuhi persyaratan standar kesehatan Peraturan Menteri Kesehatan No. 492 Tahun 2010 tentang Baku Mutu Air Minum dan Peraturan Menteri Kesehatan No. 32 Tahun 2017 tentang Baku Mutu Air Higiene
Sanitasi. Air yang tidak memenuhi standar Baku Mutu Air Sungai serta Baku Mutu Air Minum dapat menyebabkan gangguan kesehatan Water Borne Diseases (Tifoid, Kolera, Leptospirosis) (Lestari M et al, 2017).

\section{KESIMPULAN}

Pada Fasilitas Proses di PT X Sumatera Selatan Tahun 2021 didapatkan hasil penilaian risiko kesehatan kerja bahwa potensial hazard yang termasuk kategori risiko tinggi yaitu kebisingan, kategori risiko sedang yaitu hazard kimia benzene, ergonomi dan psikosisal. Sedangkan kategori risiko rendah yaitu hazard biologi water supply.

\section{UCAPAN TERIMAKASIH}

Terima Kasih peneliti ucapkan kepada semua pihak yang terlibat pada penelitian ini, khususnya kepada Universitas Sriwijaya, Fakultas Kesehatan Masyarakat, Program Studi Ilmu Kesehatan Masyarakat Pasca Sarjana Universitas Sriwijaya dan PT X Sumatera Selatan yang telah memberikan dukungan terhadap penyelesaian penelitian ini.

DAFTAR PUSTAKA

AYUDINTA, M. A., \& AYUDINTA, M. A. (2016). PENILAIAN RISIKO KESEHATAN AKIBAT FAKTOR FISIK DENGAN HEALTH RISK ASSESSMENT (HRA) DI MARGARINE PLANT PT SMART TBK (Doctoral dissertation, Universitas Airlangga).

Asnel, R., \& Pratiwi, A. (2020). ANALISIS FAKTOR-FAKTOR YANG MEMPENGARUHI KELUHAN MUSCULOSKELETAL DISORDER PADA PEKERJA LAUNDRY. Public Health and 
Safety International Journal, 1(01), 53-61.

Chusna, N. A., Huboyo, H. S., \& Andarani, P. (2017). Analisis Kebisingan Peralatan Pabrik Terhadap Daya Pendengaran Pekerja di PT. Pura Barutama Unit Pm 569 Kudus (Doctoral dissertation, Diponegoro University).

Dewi, N. F. (2020). Identifikasi Risiko Ergonomi Dengan Metode Nordic Body Map Terhadap Perawat Poli RS X. Jurnal Sosial Humaniora Terapan, 2(2).

Domínguez, C. R., Martínez, I. V., Peña, P. M. P., \& Ochoa, A. R. (2019). Analysis and evaluation of risks in underground mining using the decision matrix risk-assessment (DMRA) technique, in Guanajuato, Mexico. Journal of Sustainable Mining, 18(1), 52-59.

ELPHIANA E G, E. E., Diah, Y. M., \& Zen, M. K. (2017). Pengaruh Keselamatan dan Kesehatan Kerja Terhadap Kinerja Karyawan PT. Pertamina EP Asset 2 Prabumulih (Doctoral dissertation, Sriwijaya University).

EU OSHA. (2007). K3 dalam angka: Pekerja muda - Fakta dan angka. Laporan observatorium risiko Eropa. Luksemburg: Kantor untuk Publikasi Resmi Masyarakat Eropa.

International Labour Organization (ILO). 2013. Workplace Stress: A collective challenge. World Day For Safety.

ILO. 2018. Meningkatkan Kesehatan dan Keselamatan Pekerja Muda. Jakarta: Kantor Perburuhan Internasional.

Kartikasari, D., Nurjazuli, N. and Rahadjo, M., (2016). Analisis Risiko Kesehatan Pajanan Benzene pada Pekerja di Bagian Laboratorium Industri Pengolahan Minyak Bumi. Jurnal Kesehatan Masyarakat (Undip), 4(4), pp.892-899.
Lestari, M., Purba, I.G. and Camelia, A., (2017). Penilaian Risiko Kesehatan Kerja di Bengkel Auto 2000. Jurnal Ilmu Kesehatan Masyarakat, 8(3), pp.145-159.

Menaker, (2018). Peraturan Menteri Ketenagakerjaan Republik Indonesia Nomor 5 Tahun 2018 tentang keselamatan dan kesehatan kerja lingkungan kerja,

Menkes, (2010). Peraturan Menteri Kesehatan No. 492 Tahun 2010 tentang Baku Mutu Air Minum.Peraturan

Menkes, (2017). Peraturan Menteri Kesehatan No. 32 Tahun 2017 tentang Baku Mutu Air Higiene Sanitasi.

Pramesti, N. Y., \& Damayanti, R. W. (2017). Analisis Kebisingan Ruang Weaving Unit Weaving B di PT. Delta Merlin Dunia Textile IV. Prosiding SNST Fakultas Teknik, 1(1).

Prasetyo, R. D. (2018). Penilaian Risiko Kesehatan Faktor Bahaya Fisika dan Kimia pada Mine Production B Area Ciguha Utama PT Antam Tbk. Unit Bisnis Pertambangan Emas Pongkor.

Rohani, J. M., Adeyemi, A. J., Aziz, R. A., \& Rani, M. R. A. (2018). The inter-rater and intra-rater reliability analysis of workplace ergonomic risk assessment. Jurnal Teknologi, 80(1).

Safitri, A. G., Widjasena, B., \& Kurniawan, B. (2017). Analisis Penyebab Keluhan Neck Pain pada Pekerja di Pabrik Sepatu dan Sandal Kulit Kurnia di Kota Semarang. Jurnal Kesehatan Masyarakat (e-Journal), 5(3), 234-239.

Shell HSSE Department. (2001). Shell Health Risk Assessment Yellow Guide. USA: Shell Oil Company.

Susilaningtyas, M., Suwondo, A. and Ekawati, E., (2018). HUBUNGAN PAPARAN BENZENE DENGAN FUNGSI PARU PADA AWAK 
MOBIL TANGKI BBM DI PT. X SEMARANG. Jurnal Kesehatan Masyarakat (e-Journal), 6(5), pp.579586.

World Health Organization (WHO). (2003). Work Organization and Stress. Protecting Workers' Health Series, No. 3. Geneva: World Health Organization
World Health Organization (WHO). (2010). Health Impact of Psychosocial Hazard at Work: An Overview World Health Organization (WHO). 2013. Work Organization and Stress. United Kingdom: WHO 